\title{
The Expression and Prognosis of Caspase-9 in Hepatocellular Carcinoma
}

\section{Xiaohui SUN1, Lingling SUN², Chen Jiang³, Zhiqiang QIN¹, Mei}

\author{
LIN1 \\ ${ }^{1}$ Department of Pathology, Medical College of Qingdao University, 308 Ningxia Road, Shinan District, Qingdao, \\ 266071, Shandong, China \\ ${ }^{2}$ Department of Pathology, Affiliated Hospital of Qingdao University, Qingdao, 266071, China \\ ${ }^{3}$ Department of Pathology, Qingdao Municipal Hospital, Qingdao, 266021, China
}

\begin{abstract}
Objective: We aim to investigate the expression of Caspase- 9 and its prognostic significance in hepatocellular carcinoma (HCC). Methods: The expression of Caspase-9 in 108 specimens of HBV-related HCC, 30 cases of cirrhosis tissue and 20 cases of normal liver tissue was examined by immunohistochemical staining. And we explored the relationship of Caspase-9 with clinicopathological parameters, 5-year overall survival (OS) and disease-free survival (DFS) in HCC patients. Results: Caspase-9 expression in HCC was significantly higher than that in normal liver tissue $\left(\chi^{2}=4.349, \mathrm{P}=0.037\right)$. The expression of Caspase- 9 was not different both between normal liver tissue and cirrhosis, cirrhosis and HCC $\left(\chi^{2}=0.347, \mathrm{P}=0.556 ; \chi^{2}=2.713, \mathrm{P}=0.100\right)$. Caspase-9 expression in HCC was correlated with Edmondson grade and satellite nodule $(\mathrm{P}=0.001$ and $\mathrm{P}=0.005$, respectively). Survival analysis showed that Caspase-9 expression was associated with OS and DFS ( $P=0.001$ and $\mathrm{P}=0.006$, respectively). Conclusion: The expression of Caspase-9 correlated with the carcinogenesis and progression of HCC. Assessment the expression of Caspase-9 may predict the recurrence and survival of HCC patients.
\end{abstract}

Keywords: Caspase-9; Apoptosis; Prognosis; Hepatocelluar carcinoma

\section{Introduction}

Hepatocellular carcinoma is one of the common malignant tumors threatening the health of humans[1]. Apoptosis plays an important role in the pathogenesis and progression of tumors[2]. The activation of cysteinyl aspartate specific proteinase (Caspase) is the core step to regulate apoptosis[3]. There are two pathways of apoptosis[4]. One is the extrinsic pathway triggered by the death receptor and the ligand system. The other one is known as intrinsic pathway which is mediated by mitochondria and cytochrome c (Cyto-C). Cyto-C is released by mitochondria. It can combine Apaf-1 and ATP to activate Caspase-9. Caspase- 9 can then invoke the activation of the downstream effector Caspase- 3 and Caspase-7 to induce apoptosis. Caspase- 9 is the foremost initiator in the process of intrinsic apoptosis[5,6]. The abnormal expression of Caspase-9 and its association with pathological parameters have been reported in many tumors, such

This article is published under the terms of the Creative Commons Attribution License 4.0

Author(s) retain the copyright of this article. Publication rights with Alkhaer Publications.

Published at: http://www.ijsciences.com/pub/issue/2017-04/

DOI: 10.18483/ijSci.1254; Online ISSN: 2305-3925; Print ISSN: 2410-4477 
as breast carcinoma[7], pancreatic carcinoma[8], prostate cancer[9], thyroid carcinoma[10], colorectal cancer[11], gastric carcinoma[12] and $\mathrm{HCC}[13,14]$. However, the association of Caspase-9 expression and the prognosis of $\mathrm{HCC}$ patients has not been reported. In the present study, we investigated the expression of Caspase-9 and its association with clinical parameters and prognosis in HCC.

\section{Material and methods}

\section{Patients and samples}

We selected 108 HCC specimens (11 women and 97 men, age from 22 - 82, median age 55) from patients who underwent hepatectomy during 2003 - 2007 in the Affiliated Hospital of Qingdao University. All of the patients were $\mathrm{HbsAg}$ positive. And we selected 30 cases of cirrhosis tissues from patients with liver cirrhosis (8 women and 22 men, age from 35 - 66, median age 51.5) and 20 cases of normal liver tissues obtained from patients with hepatolithiasis (5 women and 15 men, age from 30 - 63, median age 50.5). None of these patients has undergone any pre-operative therapy. The study was approved by the local ethics committee.

\section{Immunohistochemical staining and assessment}

At first, formalin-fixed, paraffin-embedded $3-\mu \mathrm{m}$ sections were prepared.

After deparaffinization and rehydration, antigen retrieval was conducted by boiling the slides for 2 min in a pressure cooker filled with $10 \mathrm{mM}$ citric buffer ( $\mathrm{PH}=6.0$, Maxin-bio, Fuzhou, China). After cooling at room temperature, the slide were immersed in $3 \%$ hydrogen peroxide for $10 \mathrm{~min}$ to block endogenous peroxidase activity. Subsequently, the slides were incubated in rabbit anti-Caspase-9 polyclonal antibody (Boster, Wuhan, China) at a dilution of $1: 150$ at $37.0^{\circ} \mathrm{C}$ for $60 \mathrm{~min}$. The slides were then incubated in HRP-Ploymer anti-Rabbit antibody (Maxin-bio, Fuzhou, China, KIT-5005) for $10 \mathrm{~min}$ at $37.0^{\circ} \mathrm{C}$. The slides were then dyed with diaminobezidine tetrahydrochloride (DAB,
Maxin-bio, Fuzhou, China). At last, the slides were counterstained with hematoxylin. Between each step, we used PBS to wash the slides for 3 times. We chose PBS to replace the primary antibody as a negative control.

Immunohistochemical assessment was performed by two investigators respectively without any knowledge of the clinicopathological details of the patients. For each slide, we chose five fields at X400 magnification randomly. We used a scoring system based on staining intensity and percentage of positive part. The staining intensity was scored as "0" (no staining), “1” (weakly stained), “2”(moderately stained) and " 3 " (strongly stained). The percentage of positive tumor cells was scored as " 0 " $(<5 \%)$, “ 1 ” (5 - 25\%), "2" (26 - 50\%), “3” (51 - 75\%) and "4" (> $75 \%)$. The final score was calculated by multiplying the staining intensity score by the score of the percentage positive part. Caspase- 9 expression was defined: negative when score less than 8 or positive when score equal or more than 8 .

\section{Statistical analysis}

SPSS 17.0 software (SPSS Inc.) was used for statistical analysis. The comparison of Caspase-9 expression in different tissues and the relationship of Caspase-9 expression of HCC and clinicopathological parameters were analyzed by chi-square $\left(\chi^{2}\right)$ test or Fisher's exact test. Kaplan-Meier survival analysis was used to analyze the 5-year OS and DFS. The log-rank test was performed to compare the differences. $\mathrm{P}<0.05$ was considered statistically significant.

\section{Results}

Expression of Caspase-9 in normal liver, cirrhosis and $\mathrm{HCC}$

The positive rate of Caspase- 9 in normal liver, cirrhosis and HCC was (7/20) 35.0\%, (13/30) $43.3 \%$ and (65/108) 60.2\% respectively (Table 1). The expression of Caspase-9 in HCC was higher than that 
in normal liver tissue $\left(\chi^{2}=4.349, \mathrm{P}=0.037\right)$. The expression of Caspase- 9 was not different both between normal liver tissue and cirrhosis, cirrhosis and $\mathrm{HCC}\left(\chi^{2}=0.347, \mathrm{P}=0.556\right.$ and $\chi^{2}=2.713, \mathrm{P}=$ 0.100). The typical staining patterns of Caspase-9 in normal liver, cirrhosis and HCC tissue were shown in Figure 1.

Association of Caspase-9 expression and clinicopathological parameters

The expression of Caspase-9 in HCC was correlated with Edmondson grade and satellite nodule $(\mathrm{P}=$ 0.001 and $\mathrm{P}=0.005$, respectively). There was no significant association between Caspase- 9 expression and age, sex, tumor size, tumor number, AFP (alfha-fetoprotein), vascular invasion, capsule invasion, TNM stage, and lymphatic metastasis (Table 2).

\section{Expression of Caspase-9 and prognosis}

All of the $108 \mathrm{HCC}$ patients were followed up for 60 months after the operation. The survival analysis revealed that the expression of Caspase-9 was associated with OS and DFS $(\mathrm{P}=0.001$ and $\mathrm{P}=$ 0.006 , respectively) (Table 3 ). And patients with positive Caspase-9 expression had favorable OS and DFS than those with negative Caspase- 9 expression (Figure 2).

\section{Discussion}

The carcinogenesis of tumors is closely related to the imbalance of cell proliferation and cell death[15]. Apoptosis is one of the mechanism of cell death by which unwanted, senescent and damaged cells can be eliminated to achieve the homeostasis of organs. Dysregulation of apoptosis is closely related to many liver diseases, for instance, alcoholic liver disease, viral hepatitis, cholestatic liver diseases and the carcinogenesis of HCC[16]. Caspase-9 is the initiator of the intrinsic pathway of apoptosis. It plays an irreplaceable role in apoptosis [17].
Previous studies showed that Caspase-9 expression increased in breast carcinoma[7] and pancreatic carcinoma[8]. On the contrary, decreased Caspase-9 expression was reported in prostate cancer[9], thyroid carcinoma[10], colorectal cancer[11] and gastric carcinoma[12]. Former studies revealed that Caspase-9 protein expression was lower in HCC than that in normal tissue[13] or adjacent non-tumor tissue[14]. Chen et al. showed that there was no difference of Caspase- 9 mRNA level between HCC and normal tissue[18]. In this study, the expression of Caspase- 9 protein was increased in HCC compared to normal liver tissues. This suggested that Caspase- 9 might play a role in the occurrence of HCC. Apoptosis acts a significant part in preventing the occurrence of cancer[15]. The inhibition of apoptosis can lead to the abnormal proliferation of tumor cells. In the present study, Caspase-9 expression was higher in HCC than in normal tissue. A study reported that apoptotic index was not increased in Caspase-3 positive expression tissue compared with Caspase-3 negative expression tissue[19]. Therefore, although Caspase- 9 is the foremost initiator of intrinsic apoptosis, the expression of Caspase- 9 protein may not represent the level of apoptosis. In addition, MUER et al. showed that the increased expression of Caspase-9 in primary colon cancer had a positive correlation with the severity of the inflammation around the tumor[20]. In the current study, all the HCC samples were HBV-related. This may help to explain the increased expression of Caspase- 9 compared to the normal liver tissue.

In previous reports, Caspase-9 expression was correlated with TNM stages, metastasis of lymph nodes and histological differentiation in pancreatic carcinoma[8] and gastric carcinoma[12]. In thyroid carcinoma, Caspase-9 was associated with TNM stages, histological differentiation, metastasis of lymph nodes and capsule invasion[10]. In HCC, studies showed that Caspase-9 expression was 
decreased in tumors with Edmondson III-IV grade[13,14]. Our results were in accordance with the previous studies. Wang et al. demonstrated that Caspase-9 expression was associated with intrahepatic or distant metastasis[21]. In this study, Caspase-9 expression was increased in tumors without satellite nodule. This indicated that Caspase-9 might play a role to inhibit the intrahepatic metastasis of HCC.

Decreased Caspase-9 expression was reported to be associated with unfavorable OS and DFS in patients with stage II colorectal cancer[11]. On the contrary, it was reported that decreased Caspase- 9 expression correlate with favorable OS of patients with pancreatic carcinoma[8]. In current study, the results of Kaplan-Meier analysis showed that patients with elevated expression of Caspase-9 had better DFS and OS. This suggested that Caspase- 9 could be used to predict both recurrence and survival of $\mathrm{HCC}$ patients.

In conclusion, increased Caspase- 9 expression might correlate with the carcinogenesis and progression of HCC. Assessment of Caspase-9 expression may predict HCC patients with unfavorable prognosis.

Declaration of Conflicts of Interest: The authors have no conflicts of interest to declare.

\section{References}

I. El-Serag HB, Rudolph KL. (2007) Hepatocellular carcinoma: epidemiology and molecular carcinogenesis. Gastroenterology. 132: 2557-2576. DOI: org/10.1053/j.gastro.2007.04.061

II. Johnstone RW, Ruefli AA, Lowe SW. (2002) Apoptosis : a link between cancer genetics and chemotherapy. Celf. 108: 153-164. DOI: 10.1007/0-387-26283-0_10

III. Zhang Q, Ma S, Liu B, Liu J, Zhu R, Li M.(2016) Chrysin induces cell apoptosis via activation of the p53/Bcl-2/caspase-9 pathway in hepatocellular carcinoma cells. Exp Ther Med. 12: 469-474. DOI: 10.3892/etm.2016.3282

IV. Druskovic M, Suput D, Milisav I. (2006) Overexpression of Caspase-9 Triggers Its Activation and Apoptosis in Vitro. Croat Med J. 47:832-840. DOI: 10.1007/s10495-006-0050-8

V. Renatus M, Stenni HR, Scott FL, Liddington RC, Salvesen GS. (2001) Dimer formation drives the activation of the cell death protease caspase-9. Proc Natl Acad Sci USA. 98: 14250-14255 . DOI: 10.1073/pnas.231465798

VI. Acehan D, Jiang X, Morgan DG, et al. (2002) Three-dimensional structure of the apoptosome:implications for assembly, pro-caspase-9 binding, and activation. Mol Cell. 9: 423-432.

VII. Wang CY, Zhang YH, Li HZ, Gao DL, Zhang L, Yin YH. (2005) Expression of Caspase-9 in breast cancer tissue. Journal of Zhengzhou University (Medical Sciences). 40: 810-812. DOI: 10.13705/j.issn.1671-6825.2005.05.004

VIII. Huang S, Feng YZ, Ren SQ. (2007) The Expression and Clinical Significance of NF- $\mathrm{BB}$ and Caspase-9 in Pancreatic Carcinoma. Suzhou University Journal of Medical Science. 27: $383-386$

IX. Ai HY, Qiu XD. (2016) Relationship between pathological characteristics of prostate cancer and MACC1, c-Met, Apaf-1 as well as Caspase-9 expression in tumor tissue. Journal of Hainan Medical University. 22: 1873-1876. DOI : 10.13210/j.cnki.jhmu.20160628.008

X. Wang YH, Yu YJ. (2013) Expression and role of Caspase-9 in thyroid carcinoma and thyroid benign tumor. Chin J Cancer Prev Treat. 20 : 354-356. DOI : 10.16073/j.cnki.cjcpt.2013.05.012

XI. Shen XG, Wang C, Li Y, et a1. (2010) Downregulation of caspase-9 is a frequent event in patients with stage II colorectal cancer and correlates with poor clinical outcome. Colorectal Dis. 12 : 1213-1218 . DOI: 10.1111/j.1463-1318.2009.02009.X

XII. Yang J, Wang MJ, Chen Y, Yan Y, Qi JM. (2016) Expression and Clinical significance of Caspase3 and Caspase9 in Gastric Carcinoma. J Clin Exp Pathol. 32: 1159-1161. DOI: 10.13315 /j.cnki.cjcep.2016.10.020

XIII. Chen LZ, Li YQ, SITU MQ, Yan SH, Li W, Wang Q. (2008) Expression and clinical significance of Caspase-9 and Ki-67 in hepatocellular carcinoma. China Medicine. 3: 657-658.

XIV. Guo XD, Li ZW, Yang M, Xiong L. (2014) Expression of Caspase-9 and Survivin in hepatocellular carcinoma tissues and its clinical significance. J Clin Hepatol. 30: 254-256. DOI: 10.3969 /j.issn.1001-5256.2014.03.014

XV. Scott KL, Alan RC. (1997) Apoptosis and carcinogenesis. British MadicalBullahn. 52:554-569.

XVI. Rust C, Gores GJ. (2000) Apoptosis and liver disease. Am J Med. 108: 567 -574 . DOI: 10.1016-s0002-9343(00)00370-3

XVII. Denault JB, Salvesen GS. (2002) Caspase: key in the ignition of cell death. Chem Rev. 102(12): 4489-4500. DOI: 10.1002/chin.200306268

XVIII. Chen H, Zhang CF, Zhang X, Wang HX, Zhao WH, Chen NL. (2010) Expression of Cytochrome c, Caspase-8 and Caspase-9 in hepatocellular carcinoma and their significance. Chin J Clinicians. 4: 2019-2023. DOI: 10.3877/cma.j.issn.1674-0785.2010.10.062

XIX. Sun BH, Zhang J, Wang BJ, Zhao XP, Wang YK, Yu ZQ, Yang DL, Hao LJ. (2000) Analysis of in vivo patterns of caspase-3 gene expression in primary hepatocellular carcinoma and its relationship to $\mathrm{p} 21^{\mathrm{WAF} 1}$ expression and hepatic apoptosis. Gastroenterol. 6: 356-360. DOI: 10.3748/WJG.v6.i3.356

XX. MUER CE, WEN B, HUANG YF, LIU J. (2014) Study on the relationship between degrees of caspase9 protein expression in primary colon cancer and inflammation around 
the tumor. JOURNAL OF NORTH SICHUAN MEDICAL COLLEGE. 29: 218-221. DOI: 10. 3969 / j. issn. 1005-3697. 2014. 03.01

XXI. Wang J, Dou ZX, Wang HC, Zhang WL, Wang YD. (2009)
Expressions of survivin and caspase-9 in human primary hepatocellular carcinoma tissues and their significances. Journal of Jilin University. 35: 1119-1122. DOI: $10.13481 /$ j.1671-587x.2009.06.055
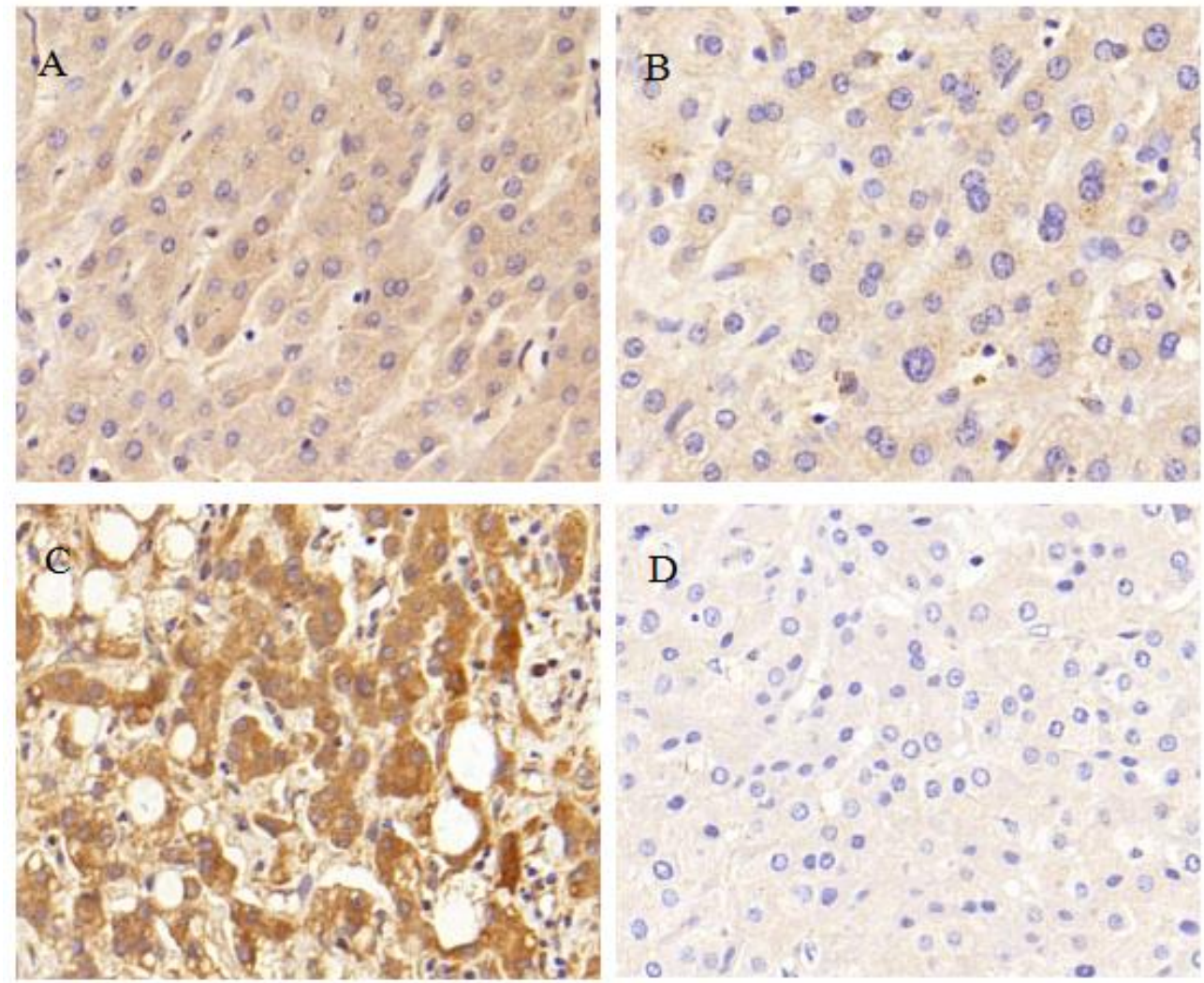

Figure 1 Immunohistochemical expression of Caspase-9 in normal liver, cirrhosis and HCC tissues. A: Expression of Caspase-9 in normal liver tissue; B: Expression of Caspase-9 in cirrhosis tissue; C: Positive expression of Caspase-9 in Edmondson I-II grade HCC tissues; D: Negative expression of Casapse-9 in Edmondson III-IV grade HCC tissues. Original magnification X400. 

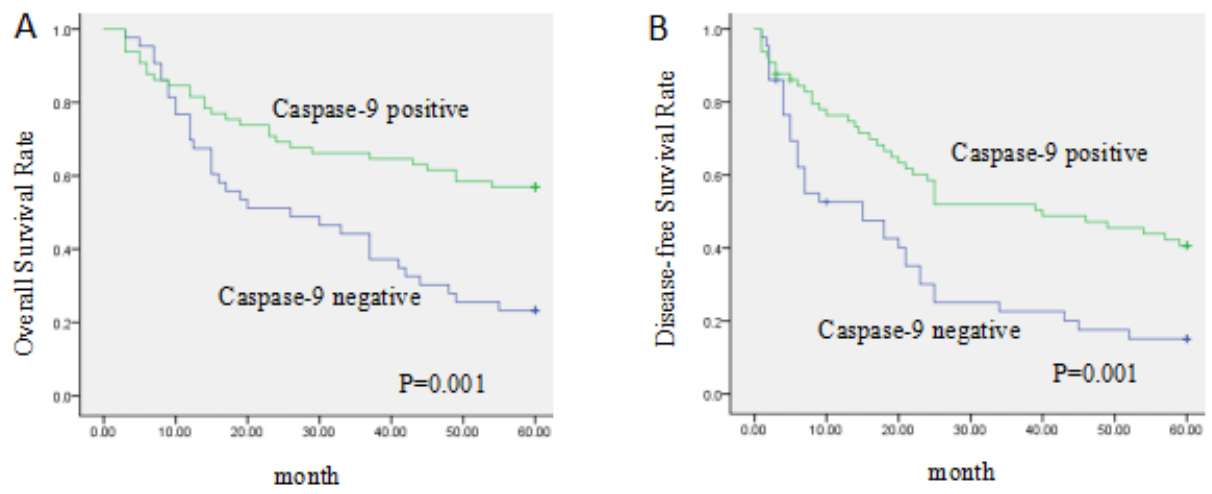

Figure 2 Overall survival and disease-free survival by Kaplan-Meier analysis according to Caspase-9 expression. A: Patients with positive Caspase-9 expression had a favorable overall survival; B: Patients with positive Caspase-9 expression had a favorable disease-free survival.

Table 1 Expression of Caspase9 in normal liver, cirrhosis and HCC

\begin{tabular}{lllc}
\hline \multirow{2}{*}{$\begin{array}{l}\text { ifferent } \\
\text { groups }\end{array}$} & \multicolumn{2}{c}{ Caspase-9 } & Positive rate \\
\cline { 2 - 3 } & positive & negative & $(\%)$ \\
\hline RN & 7 & 13 & 35.0 \\
CIRR & 13 & 17 & 43.3 \\
HCC & 65 & 43 & 60.2 \\
\hline
\end{tabular}

RN: normal liver tissue

CIRR: cirrhosis tissue 
Table 2 Correlation of Caspase- 9 with clinicopathological parameters in HCC

\begin{tabular}{|c|c|c|c|c|}
\hline \multirow{2}{*}{$\begin{array}{l}\text { Clinicopathological } \\
\text { parameters }\end{array}$} & \multirow{2}{*}{$\mathrm{N}$} & \multicolumn{2}{|c|}{ Caspase-9 } & \multirow{2}{*}{$\mathrm{P}$} \\
\hline & & Pos & gative & \\
\hline Age & & & & 0.665 \\
\hline$<55 y$ & 53 & 33 & 20 & \\
\hline$\geq 55 y$ & 55 & 32 & 23 & \\
\hline Sex & & & & $0.356^{1}$ \\
\hline Male & 96 & 56 & 40 & \\
\hline Female & 12 & 9 & 3 & \\
\hline AFP & & & & 0.844 \\
\hline$\leq 50 \mathrm{ng} / \mathrm{ml}$ & 54 & 33 & 21 & \\
\hline$>50 \mathrm{ng} / \mathrm{ml}$ & 54 & 32 & 22 & \\
\hline Tumor size & & & & $0.760^{1}$ \\
\hline$<3 \mathrm{~cm}$ & 12 & 8 & 4 & \\
\hline$\geq 3 \mathrm{~cm}$ & 96 & 57 & 39 & \\
\hline Edmondson grade & & & & $0.001^{\mathrm{a}}$ \\
\hline I-II & 72 & 51 & 21 & \\
\hline III-IV & 36 & 14 & 22 & \\
\hline Vascular invasion & & & & 0.448 \\
\hline Yes & 16 & 11 & 5 & \\
\hline No & 92 & 54 & 38 & \\
\hline Tumor number & & & & 0.901 \\
\hline Single & 91 & 55 & 36 & \\
\hline Multiple & 17 & 10 & 7 & \\
\hline Satellite nodule & & & & $0.005^{\mathrm{a}}$ \\
\hline Yes & 21 & 7 & 14 & \\
\hline No & 87 & 58 & 29 & \\
\hline Lymphatic metastasis & & & & $1.000^{1}$ \\
\hline Yes & 4 & 2 & 2 & \\
\hline No & 104 & 63 & 41 & \\
\hline TNM Stage & & & & 0.841 \\
\hline I-II & 79 & 48 & 31 & \\
\hline III-IV & 29 & 17 & 12 & \\
\hline Capsule invasion & & & & 0.570 \\
\hline Yes & 81 & 50 & 31 & \\
\hline No & 27 & 15 & 12 & \\
\hline
\end{tabular}


a denote for a significant P-value of $<0.05$
${ }^{1}$ performed by Fisher's exact test

Table 3 Univariate analysis of OS and DFS

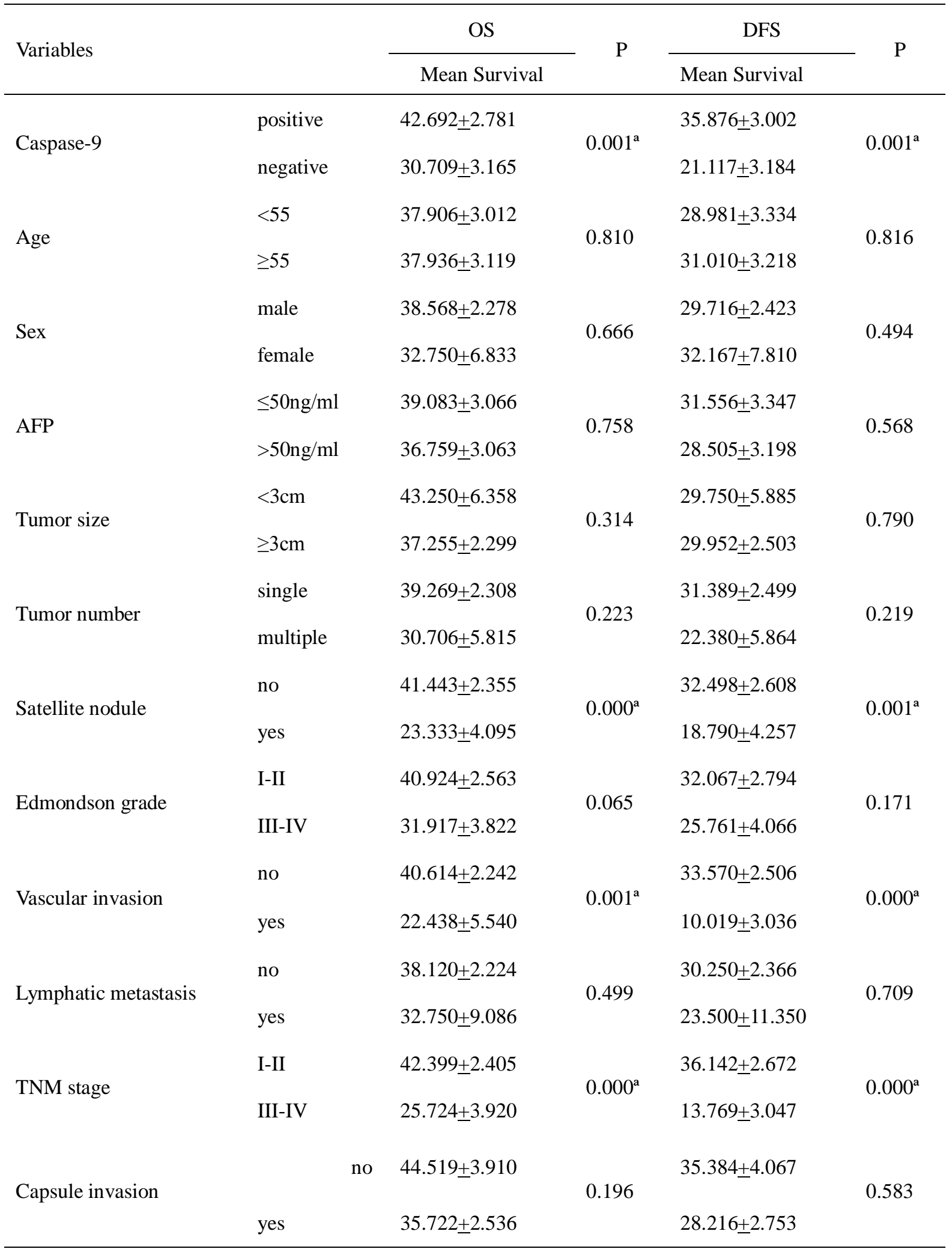

${ }^{\text {a }}$ denote for a significant $\mathrm{P}$-value of $<0.05$ 